\title{
THE FREQUENCY OF VISCERAL AND PHENOTYPIC MARKERS IN PATIENTS WITH THE COMBINATION OF UNDIFFERENTIATED CONNECTIVE TISSUE DISEASE AND GASTROESOPHAGEAL REFLUX DISEASE
}

DOI: 10.36740/WLek202007134

\author{
Iryna B. Romash, Vasyl G. Mishchuk \\ IVANO-FRANKIVSK NATIONAL MEDICAL UNIVERSITY, IVANO-FRANKIVSK, UKRAINE
}

\begin{abstract}
The aim: The aim of the research was to study the prevalence of visceral and phenotypic markers of UCTD syndrome in patients with GERD for the purpose of early diagnosis of this comorbidity.

Materials and methods: The study included 120 patients: 75 patients (Group II) - GERD was on the background of UCTD, 45 (Group I) - the patients with GERD. The average age of the patients was $42.05 \pm 6.5$ years. Evaluations of UCTD's were performed accordingly to the criteria recommended by M. Moska et al., A. Doria et al., T. I. Kadurina, L. M. Abbakumova in the modification of T. Milkovskaya-Dimitrova, and the degree of their expression on the scale of T. Y. Smolnova.

Results: Among the examined patients, the specific criteria for the certain connective tissue diseases were detected in the patients with UCTD from 2.7 and $20.0 \%$ more often. Bone, joint and skin phenotypic signs of dysplasia were observed in patients with GERD associated with UCTD by 4-4.5 times more often. Various abnormalities of internal organs development were detected in the majority of patients of Group II, namely in $88.0 \%$, and only in $6.6 \%$ of the patients of Group I. According to the data on daily pH monitoring, esophagus AET constituted $4.6 \%$ of the total monitoring period in Group I and $5.48 \%$ in the patients of Group II. The number of refluxes with pH $<4$ recorded in the patients of Group I constituted $57 \pm 8$ episodes, and $79 \pm 6$ episodes in the patients of Group II.

Conclusions: The obtained data indicated that the number of pathological GER was significantly higher in the setting of comorbidity. Our research also showed that the chances of diagnosing Reynaud's Syndrome, arthralgia, unmotivated body weight loss, dysphagia, skin rash, oral ulcers, proximal muscle weakness in the patients with GERD associated with UCTD are higher in comparison with the patients with GERD without comorbidity $(p<0.05)$. This should necessarily be taken into account in the early diagnosis and when assigning a complex therapy in case of this pathology.
\end{abstract}

KEY WORDS: gastroesophageal reflux disease, undifferentiated connective tissue dysplasia, visceral and phenotypic markers

Wiad Lek. 2020;73(7):1492-1498

\section{INTRODUCTION}

Modern medicine is special by the reason that diseases lose their mono- nosological character and more often manifest in comorbide course. In recent decades, the incidence of undifferentiated connective tissue disease (UCTD) has increased in Ukraine, with a frequency of diagnosis from $9 \%$ to $85 \%$ of cases. UCTD refers to unclassified systemic autoimmune diseases. Such diagnosis is made if the patient has had signs and symptoms indicative of connective tissue lesions for three years or more but which do not correspond in their set to the criteria for any of differentiated connective tissue diseases in the presence of low titer of antinuclear antibodies in blood serum [1-6]. These data are also confirmed by the Project Regulation ReCONNET of the European Reference Networks (ERN) according to which the issue of referring patients to UCTD group is possible if its manifestations are not specific to such connective tissue diseases as rheumatoid arthritis, scleroderma, widespread vasculitis, myositis, systemic lupus erythematosus, Sjogren's syndrome $[1,7,8]$.
According to the scientific data, UCTD can cause dysplastic changes in the connective tissue of various organs and systems and, accordingly, be a premorbid background for the development of many pathological conditions and chronic diseases. The digestive system is the second by the highest level of collagenization after the cardiovascular system, changes in it are particularly often observed in case of UCTD. It causes changes in the length and size of the digestive system and the esophagus first of all, which is likely to be due to its mesenchymal origin [7]. According to the scientific studies, gastrointestinal tract lesions were observed in $80 \%$ of patients in the German national cohort, and changes in the esophagus were noted most often [9]. In particular, gastroesophageal reflux disease (GERD) was diagnosed in $29.0 \%$ of patients with UCTD, while it was observed only in $2.0 \%$ of the examined patients in case of UCTD absence [10]. This syndrome changes the clinical findings of the underlying disease, promotes its prolonged and atypical course, low effectiveness of the therapy, complications and disability in the young age [11]. 


\section{THE AIM}

The aim of the research was to study the prevalence of visceral and phenotypic markers of UCTD syndrome in patients with GERD for the purpose of early diagnosis of this comorbidity.

\section{MATERIALS AND METHODS}

The research was conducted at two settings: the Therapeutic Department of the University Clinic of Ivano-Frankivsk National Medical University (IFNMU) and the Therapeutic Department №2 of Ivano-Frankivsk Central City Clinical Hospital. During 2016-2019, 120 patients were examined in both centers according to a single algorithm (65 men and 55 women with an average age of $42.05 \pm 6.5$ who underwent inpatient treatment of GERD. GERD developed on the background of UCTD syndrome in 75 patients (Group II) and no signs of connective tissue dysplasia in case of GERD were noted in 45 patients (Group I). 25 men and 20 women were examined in Group I and 40 men and 35 women were examined in Group II.

Targeted search for visceral and phenotypic signs of UCTD syndrome was performed in each patient in addition to traditional clinical and laboratory-instrumental research methods. They were evaluated according to the criteria recommended by Moska et al [1999, 2006], A. Doria et al [2005], expert tables with a score assessment of the relevance of a number of clinical, laboratory and instrumental CTD indicators recommended by T.I. Kaduryna (2009), L.N. Abakumova in the modification by T. Milkovska-Dymytrova, the degree of their severity according to the scale by T.Yu. Smolnova [2009]. The presence of joint hypermobility signs was also determined according to Carter \& Wilkinson criteria (1964) modified by Beighton $(1983)[12,13]$. The maximum value of the indicator was 9 points in case of bilateral localization. The state of hypermobility was determined when scoring from 4 to 9 points. Walker-Murdoch sign (put together thumb and little finger totally encircle the wrist) and thumb sign were additionally detected.

The research was approved by the Bioethics Committee of Ivano-Frankivsk National Medical University and conducted according to the principles of the Helsinki Declaration. All patients signed a voluntary informed consent before the study.

GERD was diagnosed according to the criteria of the unified clinical protocol (the Order of the Ministry of Health of Ukraine from October 31, 2013 № 943) taking into account complaints, the data of endoscopic examination, results of daily intragastric $\mathrm{pH}$-metry. Criteria for inclusion in the study were the presence of typical GERD clinical manifestations such as heartburn, regurgitation, pain in the epigastric region and behind the sternum, dysphagia, dry cough, esophagitis of different degrees according to the results of esophagogastroduodenoscopy (EGD). Los Angeles (LA) classification (1998) was used for the endoscopic assessment of the degree of esophagus lesion. The exclusion criteria included peptic ulcer, surgical intervention on the gastrointestinal tract organs; malignant lesions of any localization, prolonged use of nonsteroidal anti-inflammatory drugs, diabetes mellitus, pregnancy, lactation, severe somatic diseases.

Daily $\mathrm{pH}$ monitoring (according to Professor V.N. Chernobrovyi's method) was conducted in order to determine pathological gastroesophageal reflux (GER). Introduced transnasally $\mathrm{pH}$ - microprobe was used in the course of examination. The electrode was placed $5 \mathrm{~cm}$ above the proximal edge of the lower esophageal sphincter. The patients were recommended to stop using coffee, fruit juices and antacids, and they were suggested to keep a diary of events, including a clear indication of the hour of reflux symptoms. pH-metry data were registered by the portable apparatus Acidogastrograph "AG-1pH-M" (Ukraine).

The statistical analysis of the results was performed using STATISTICA 7.0 software packages and the package of statistical functions of Microsoft Excel. Arithmetic mean $(M)$ and standard error $( \pm m)$ were used to describe the quantitative characteristics. The reliability of the obtained indices was confirmed by calculating the errors for relative values, and the probability of the difference in the data in the comparable groups was proved on the basis of the calculation of $\mathrm{t}$-coefficient (Student t-test) and determination of precise prognosis according to the accuracy table. The comparison of qualitative features was performed by chi-square method calculation using the analysis of chi-square distribution table. The odds ratio (OR), the standard error of odds ratio (S) were calculated, the statistical significance of this connection was evaluated by calculating $95 \%$ of its confidence interval (CI): its lower and upper boundaries. The indicator of 0.05 was considered to be the critical level of significance when checking the statistical hypotheses.

\section{RESULTS AND DISCUSSION}

The data on visceral and phenotypic signs of UCTD in the examined patients are presented in Table I and Table II.

According to the data presented in Table I., the abnormalities of the internal organs development were detected in $66(88.0 \%)$ patients of Group II forming the majority, while they were observed only in $3(6.6 \%)$ patients of Group I.

In particular, hiatal hernia was diagnosed in $20.0 \%$ of patients with comorbid pathology. Cardia insufficiency was recorded 2.75 times more often in the patients with GERD developed on the background of UCTD. The examined patients with UCTD were also diagnosed with ptosis of the transverse colon by 3.7 times more frequently, dolichosigmoid by 2.6 times more often, colon diverticulum by 7 times. Ileocecal valve insufficiency was determined in $9.3 \%$ of cases in the patients with comorbid pathology. UCTD often manifested in abnormalities and functional disorders of the biliary system which may be the basis for duodenogastric reflux development. Nephroptosis and ectopic kidney ( $15.5 \%$ vs. $46.6 \%)$, pelvic ptosis ( $22.2 \%$ vs. $80.0 \%$ ) occurred also more frequently in the patients with this comorbidity. Mitral valve prolapse was diagnosed in 49 
Iryna B. Romash, Vasyl G. Mishchuk

Table I. Visceral signs of UCTD in the patients examined for gastroesophageal reflux disease and its combination with undifferentiated connective tissue dysplasia

\begin{tabular}{|c|c|c|c|c|c|c|}
\hline \multirow[t]{2}{*}{ Visceral signs of UCTD } & \multicolumn{2}{|c|}{$\begin{array}{c}\text { Group I } \\
\text { GERD }\end{array}$} & \multicolumn{2}{|c|}{$\begin{array}{c}\text { Group II } \\
\text { GERD + UCTD }\end{array}$} & \multirow[t]{2}{*}{$x^{2}$} & \multirow[t]{2}{*}{$p x^{2}$} \\
\hline & abs & $\%$ & abs & $\%$ & & \\
\hline Cardia insufficiency & 8 & 17.7 & 22 & 29.3 & 2.003 & 0.157 \\
\hline Diaphragmatocele & - & - & 15 & 20.0 & 10.286 & 0.002 \\
\hline Gastroptosia & 7 & 15.5 & 13 & 17.3 & 0.064 & 0.801 \\
\hline Ptosis of the transverse colon & 3 & 4.5 & 11 & 14.7 & 1.747 & 0.187 \\
\hline Biliary dyskinesia & 8 & 17.7 & 25 & 33.3 & 3.413 & 0.065 \\
\hline Gallbladder abnormalities & 5 & 11.1 & 65 & 86.6 & 66.057 & $<0.001$ \\
\hline Dolichosigmoid & 8 & 17.7 & 21 & 28.0 & 1.604 & 0.206 \\
\hline Colon diverticulum & 2 & 4.4 & 14 & 18.7 & 4.923 & $<0.05$ \\
\hline Ileocecal insufficiency & - & - & 7 & 9.3 & 4.460 & $<0.05$ \\
\hline Nephroptosis and hepatic dystonia & 7 & 15.5 & 35 & 46.6 & 11.966 & $<0.001$ \\
\hline Pelvic ptosis & 10 & 22.2 & 60 & 80.0 & 38.629 & $<0.001$ \\
\hline Supplemental chord of the left ventricle & 4 & 8.8 & 35 & 46.6 & 18.297 & $<0.001$ \\
\hline Mitral valve prolapse & 7 & 15.5 & 49 & 65.3 & 28.000 & $<0.001$ \\
\hline Abnormal kidney development & 2 & 4.4 & 24 & 32 & 12.583 & $<0.001$ \\
\hline
\end{tabular}

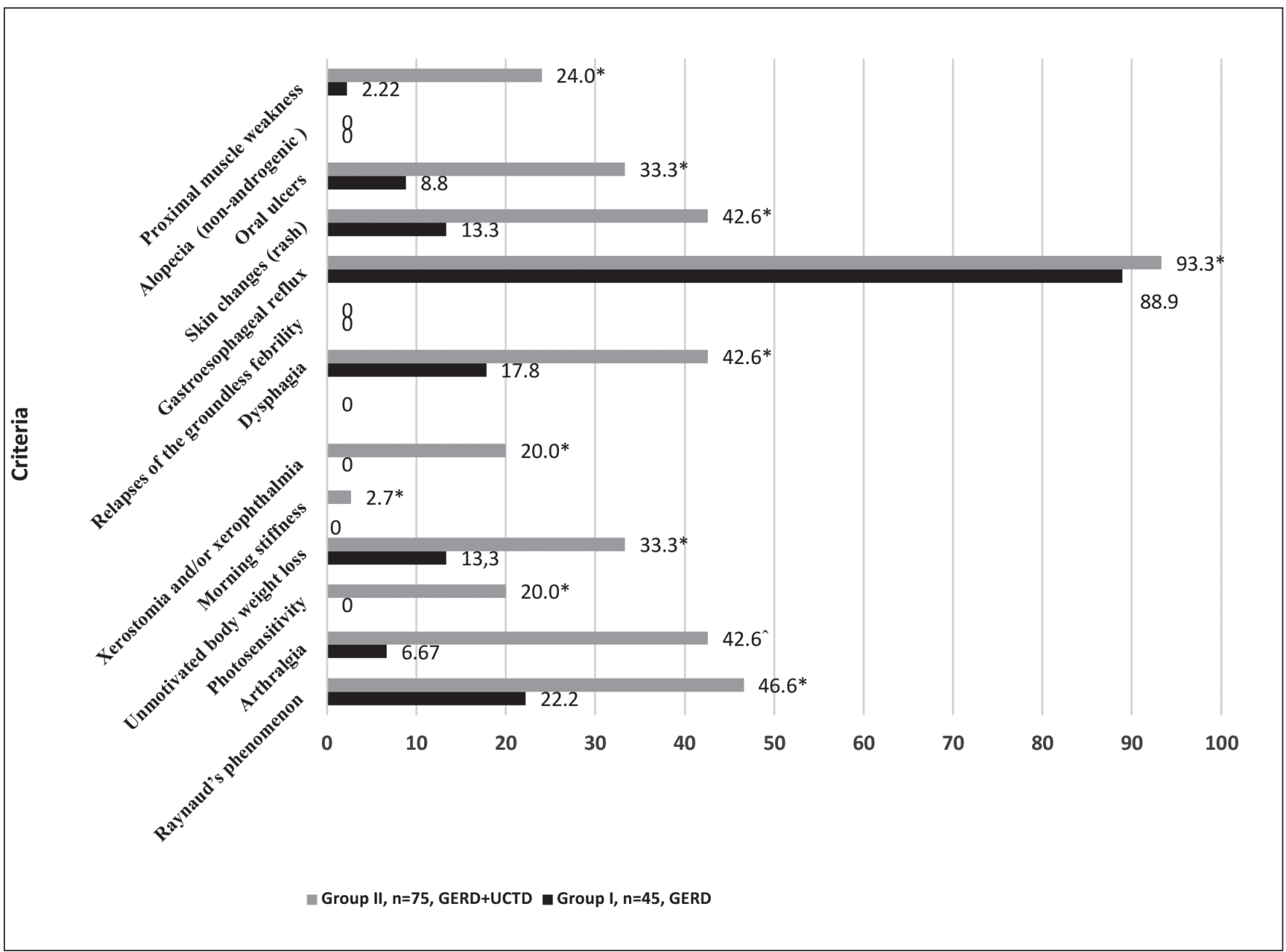

Note: The data are reliable between the study groups: ${ }^{*}-(p<0.05) i^{\wedge}-(p<0.001)$.

Fig.1. The frequency of UCTD criteria detection in the patients with GERD and its combination with this pathology according to M. Moska et al [1999, 2006, 2014] and A. Doria et al. [2005]. 
Table II. Phenotypic signs of UCTD in the examined patients according to the criteria of T.I. Kadurina, L. N. Abakumova in the modification of T. Milkovska-Dymytrova [2008]

\begin{tabular}{|c|c|c|c|c|c|c|}
\hline \multirow{2}{*}{$\begin{array}{c}\text { Clinical groups } \\
\text { Phenotypic signs of UCTD }\end{array}$} & \multicolumn{2}{|c|}{$\begin{array}{l}\text { Group I } \\
\text { GERD } \\
(n=45)\end{array}$} & \multicolumn{2}{|c|}{$\begin{array}{c}\text { Group II, } \\
\text { GERD + UCTD } \\
(n=75)\end{array}$} & \multirow[t]{2}{*}{$\underset{d f=1}{X^{2}}$} & \multirow[t]{2}{*}{$p X^{2}$} \\
\hline & abs. & $\%$ & abs. & $\%$ & & \\
\hline \multicolumn{7}{|c|}{ Bone: } \\
\hline Asthenic bodybuild & 9 & 20.0 & 66 & 88.0 & 55.488 & $<0.001$ \\
\hline Arachnodactyly & 7 & 15.5 & 66 & 88.0 & 61.950 & $<0.001$ \\
\hline Vertebral deformity: scoliosis/ kyphosis & 6 & 13.3 & 60 & 80.0 & 50.505 & $<0.001$ \\
\hline Chest distortion & 5 & 11.1 & 45 & 60.0 & 27.657 & $<0.001$ \\
\hline Cranial deformation & 3 & 6.66 & 15 & 20.0 & 3.922 & 0.048 \\
\hline Sandal gap & - & - & 5 & 6.66 & 3.130 & 0.077 \\
\hline Flat feet & 8 & 17.7 & 32 & 42.66 & 7.840 & 0.006 \\
\hline High roof of the mouth or Gothic palate & 5 & 11.1 & 15 & 20.0 & 1.600 & 0.206 \\
\hline Abnormality of occlusion & 4 & 8.8 & 9 & 12.0 & 0.282 & 0.596 \\
\hline Walker-Murdoch sign & 12 & 26.6 & 60 & 80.0 & 33.333 & $<0,001$ \\
\hline The predominance of finger IV length over finger II & 9 & 20.0 & 35 & 46.6 & 8.612 & 0.004 \\
\hline Dentition out of arch, hyperdontia & 4 & 8.8 & 26 & 34.6 & 9.967 & 0.002 \\
\hline Anterior diastema & 3 & 6.6 & 9 & 12.0 & 0.889 & 0.346 \\
\hline Defective mandibular bone & 1 & 2.22 & 12 & 16.0 & 5.527 & 0.019 \\
\hline \multicolumn{7}{|c|}{ Skin: } \\
\hline Skin hyperelastosis (from $3 \mathrm{~cm}$ ) & 5 & 11.1 & 32 & 42.6 & 13.132 & $<0.001$ \\
\hline Delicate, velvety, tender skin & 4 & 8.8 & 26 & 34.6 & 9.967 & 0.002 \\
\hline Nevus pigmentosis & 6 & 13.3 & 68 & 90.6 & 71.154 & $<0.001$ \\
\hline Percutaneous pseudoneoplasms and spheric masses & 1 & 2.22 & 5 & 6.66 & 1.170 & 0.280 \\
\hline Atrophic striae (not related to pregnancy or obesity) & 5 & 11.1 & 12 & 16.0 & 0.553 & 0.458 \\
\hline Formation of keloid scars & 4 & 8.8 & 24 & 32.0 & 8.398 & 0.004 \\
\hline Herniae and organ prolapse & 3 & 6.66 & 13 & 17.3 & 2.769 & 0.097 \\
\hline Muscular hypotonia and/or hypertrophy & 5 & 11.1 & 19 & 25.3 & 3.556 & 0.060 \\
\hline Epicanthal fold & - & - & 5 & 6.66 & 3.130 & 0.077 \\
\hline Hanging uvula & - & - & 7 & 9.33 & 4.460 & 0.035 \\
\hline Ability to roll the tongue into a tube & 6 & 13.3 & 25 & 33.3 & 5.872 & 0.016 \\
\hline Angiectasia, hematoma in case of minor blows & 3 & 6.66 & 12 & 16.0 & 2.240 & 0.135 \\
\hline Nasal septum deviation & 7 & 15.5 & 65 & 86.6 & 71.154 & $<0.001$ \\
\hline Auricle abnormalities & 3 & 6.66 & 25 & 33.3 & 11.180 & $<0.001$ \\
\hline \multicolumn{7}{|c|}{ Joints: } \\
\hline Joint hypermobility & 2 & 4.44 & 45 & 60.0 & 36.433 & $<0.001$ \\
\hline Hip dysplasia & - & - & 3 & 4.0 & 1.846 & 0.175 \\
\hline Ligament rupture in past medical history & 1 & 2.22 & 9 & 12 & 3.520 & 0.061 \\
\hline Common joint dislocation & - & - & 2 & 2.66 & 1.220 & 0.270 \\
\hline
\end{tabular}

(65.3\%) patients in Group II and only in 7 (15.5\%) patients in Group I, and supplemental chord of the left ventricle was detected in 35 patients $(46.6 \%)$ vs. 4 patients $(8.8 \%)$. Abnormal kidney development was also more common in the patients with a combination of GERD and UCTD, namely $24(32 \%)$ vs. $2(4.44 \%)$. According to the results of fibrogastroduodenoscopy, the reflux, namely esophagitis, was significantly more frequent in the patients with such combined pathology.

Such phenotypic signs of UCTD as asthenic bodybuild, arachnodactyly, vertebral deformity and chest distortion, sandal gap, joint hypermobility, skin hyperelastosis, keloid scars on the skin, hanging uvula, high roof of the mouth being the main signs of UCTD were observed from 6.6 to 
Table III. The odds ratio for UCTD criteria present in the patients with GERD and its combination with this pathology according to M. Moska et al $[1999,2006]$ and A. Doria et al [2005]

\begin{tabular}{|c|c|c|c|c|c|c|c|}
\hline № & Criteria & $\begin{array}{c}\text { Group I, } n=45 \\
\text { GERD }\end{array}$ & $\begin{array}{c}\text { Group II, n=75 } \\
\text { GERD +UCTD }\end{array}$ & $\begin{array}{c}p X^{2} \\
(d f=1)\end{array}$ & OR & $\mathbf{S}$ & $95 \% \mathrm{Cl}$ OR \\
\hline 1 & Raynaud's phenomenon & $10(22.2 \%)$ & $35(46.6 \%)$ & 0.008 & 3.063 & 0.427 & 1.327- 7.069 \\
\hline 2 & Arthralgia & $3(6.67 \%)$ & $32(42.6 \%)$ & $<0.001$ & 10.419 & 0.642 & $2.963-36.639$ \\
\hline 3 & Photosensitivity & - & $15(20.0 \%)$ & 0.002 & - & - & - \\
\hline 4 & $\begin{array}{c}\text { Unmotivated body } \\
\text { weight loss }\end{array}$ & $6(13.3 \%)$ & $25(33.3 \%)$ & 0.016 & 14.375 & 0.521 & $5.180-39.890$ \\
\hline 5 & Morning stiffness & - & $2(2.7 \%)$ & 0.270 & - & - & - \\
\hline 6 & $\begin{array}{c}\text { Xerostomia and/or } \\
\text { xerophthalmia }\end{array}$ & - & $15(20.0 \%)$ & 0.002 & - & - & - \\
\hline 7 & Dysphagia & $8(17.8 \%)$ & $26(42.6 \%)$ & 0.047 & 11.461 & 0.481 & $4.468-29.399$ \\
\hline 8 & $\begin{array}{l}\text { Relapses of the } \\
\text { groundless febrility }\end{array}$ & - & - & - & - & - & - \\
\hline 9 & Gastroesophageal reflux & $40(88.9 \%)$ & 70 (93.3\%) & 0.394 & 1.750 & 0.663 & $0.477-6.415$ \\
\hline 10 & Skin changes (rash) & $6(13.3 \%)$ & $32(42.6 \%)$ & $<0.01$ & 28.308 & 0.538 & $9.864-81.240$ \\
\hline 11 & Oral ulcers & $4(8.8 \%)$ & 25 (33.3\%) & 0.003 & 22.188 & 0.595 & $6.912-71.224$ \\
\hline 12 & $\begin{array}{c}\text { Alopecia } \\
\text { (non-androgenic) }\end{array}$ & - & - & - & - & - & - \\
\hline 13 & $\begin{array}{l}\text { Proximal muscle } \\
\text { weakness }\end{array}$ & $1(2.22 \%)$ & $18(24.0 \%)$ & 0.002 & 49.333 & 1.052 & 6.279-387.6 \\
\hline
\end{tabular}

$26.6 \%$ of cases in the patients of Group I and from $20 \%$ to $92.0 \%$ in the patients of Group II. At the same time, bone symptom complex was noted in such patients, 5 out of 14 signs of which were more significantly prevalent in the patients with comorbid pathology and included the asthenic bodybuild $\left(\chi^{2}=55.488 ; p \chi^{2}<0.001\right)$; arachnodactyly $\left(\chi^{2}=61.950 ; p \chi^{2}<0.001\right)$; vertebral deformity $\left(\chi^{2}=50.505\right.$; $\left.\mathrm{p} \chi^{2}<0.001\right)$, chest distortion $\left(\chi^{2}=27.657 ; p \chi^{2}<0.001\right)$. Skin symptom complex ranked second, and 4 out of 14 its signs such as skin hyperelastosis $\left(\chi^{2}=13.132 ; p \chi^{2}<0.001\right)$, nevus pigmentosis $\left(\chi^{2}=71.154 ; p \chi^{2}<0.001\right)$, nasal septum deviation $\left(\chi^{2}=71.154 ; p \chi^{2}<0.001\right)$, auricle abnormalities $\left(\chi^{2}\right.$ $\left.=11.180 ; p \chi^{2}<0.001\right)$ were the most characteristic for the examined patients with this comorbidity. Joint hypermobility syndrome $\left(\chi^{2}=36.433 ; p \chi^{2}<0.001\right)$ was significantly more often observed in the patients with GERD associated with UCTD.

The frequency of M. Moska and co-authors' criteria is provided in Fig. 1.

According to the figure, Raynaud's phenomenon was more often detected in the patients of Group II in comparison with Group I $(p<0.05)$. Arthralgia was diagnosed with even higher incidence in the patients of Group II, namely by $35.93 \%$ compared to Group I ( $\mathrm{p}<0.001)$, and dysphagia was detected by $24.8 \%$ more often, respectively $(\mathrm{p}<0.05)$. Periodic skin rash was more frequent by $29.3 \%$ and oral mucosa ulcers were detected by $24.5 \%$ more often in the patients of Group II $(\mathrm{p}<0.05)$. As a matter of interest, proximal muscle weakness was observed in $2.22 \%$ of patients with GERD which was less than $21.78 \%(\mathrm{p}<0.05)$ in comparison with the patients who suffered from this disease associated with connective tissue dysplasia. Groundless febrility and non-androgenic alopecia were not detected in any of the experimental groups. Symptoms such as morning stiffness were present only in $2.7 \%$ of patients, xerostomia and/or xerophthalmia was observed in $20.0 \%$ of cases, photosensitivity was noted in $20.0 \%$ of patients with comorbidity. The above mentioned criteria were absent in the patients of Group I.

We calculated the odds ratio with $95 \%$ confidence interval for the purpose of numerical expression of how the absence or presence of concomitant pathology was related to the presence or absence of a certain criterion in each of the experimental groups. The obtained data are presented in Table III.

Thus, according to the study, the chances of diagnosing the Raynaud's phenomenon in the patients with GERD associated with UCTD were higher by more than three times $(\mathrm{OR}=3.063)$ compared to the patients with GERD without comorbidity. This dependence was statistically significant, since $95 \%$ CI was within the range of 1.327-7.069 $(\mathrm{p}<0.05)$. The high probability of detecting such criteria for comorbidity as arthralgia $(\mathrm{OR}=10.419 ; 95 \% \mathrm{CI}=2.963$ 36.639), unmotivated body weight loss ( $\mathrm{OR}=14.375$; $95 \%$ $\mathrm{CI}=5.180-39.890)$, dysphagia $(\mathrm{OR}=11.461,95 \% \mathrm{CI}=4.468$ 29.399), skin rash $(\mathrm{OR}=28.308 ; 95 \% \mathrm{CI}=9.864-81.240)$, oral ulcers $(\mathrm{OR}=22.188 ; 95 \% \mathrm{CI}=6.912-71.224)$, proximal muscle weakness $(\mathrm{OR}=49.333$; 95\% $\mathrm{CI}=6.279-387.6)$ was statistically significant $(\mathrm{p}<0.05)$. As a matter of interest, the reason for the fact that the odds ratio of pathological GERD incidence in the patients with and without CTD manifestations was not significantly different $(\mathrm{OR}=1.750$; 
95\% CI=0.477-6.415) was due to the fact that this criterion was one of the main criteria of the patients' inclusion in our study.

The analysis of transnasal daily monitoring of $\mathrm{pH}$ in the lower third of the esophagus in the patients with GERD and its association with UCTD indicated that the general index of $\mathrm{pH}<4$ with the duration above normal was observed in $60 \%$ (45) of the patients in Group II and in $26.6 \%$ (12) of the patients in Group I. The number of refluxes with $\mathrm{pH}<4$ recorded in the patients of Group I was $57 \pm 8$ episodes with a total duration of $67 \pm 3$ minutes. Acid exposure time (AET) in the patients of Group I was $4.6 \%$ of the total monitoring period, which was slightly above normal. According to the Lyon Consensus, this parameter is considered to be significantly normal at a value of less than $4 \%$ and significantly pathological at a value of more than $6 \%$, and the values within this interval are considered inconclusive and require additional examinations. The number of acid refluxes constituted $79 \pm 6$ episodes with a total duration of $87 \pm 8$ minutes, $\mathrm{AET}=$ $5.48 \%$, in the patients of Group II. Time share of $\mathrm{pH}<4$ amounted to 3.5 hours in the patients of Group II and 2.9 hours in the patients of Group I $(\mathrm{p}<0.05)$. The mean De Meester score constituted 23.01 \pm 2.24 in the examined patients with GERD and $31.08 \pm 2.4$ in the patients with GERD associated with UCTD $(\mathrm{p}<0.05)$. An increase in the percentage of time with $\mathrm{pH}<4$ was also determined in the lower third of the esophagus in the upright position and in lying position in $12.3 \%$ and $7.4 \%$ of the patients with combined pathology respectively, and in $10.2 \%$ and $5.8 \%$ of patients with GERD without concomitant disease, respectively. According to the results of the correlation analysis, a direct correlation between the number of refluxes with $\mathrm{pH}<4$ with duration over 5 minutes and the degree of UCTD severity $(r=0.78)$ was established, as well as between the mean indices of the De Meester Score and the degree of UCTD severity $(r=0.68)$. We also monitored the correlation between the indicator of abnormal esophagus acidification (acid exposure timeAET) and the degree of UCTD severity $(r=0.59)$.

We used T. Yu. Smolnova scale in order to assess the aggregate and severity of CTD clinical manifestations. According to the scale, the patient was diagnosed with CTD of mild severity in case of total points up to 9, with CTD of moderate severity in case of total points from 10 to 16 , and with severe CTD in case of total points from 17. According to the presented data, the signs of CTD of mild severity were predominant in the patients of Group I, and CTD of moderate severity prevailed in Group II. UCTD of moderate severity was noted in $69.0 \%$ of the patients with combined pathology and in only $44.0 \%$ of the patients with GERD. Signs of severe UCTD were diagnosed in $4 \%$ of patients in Group II and were absent in the patients of Group I.

Thus, UCTD is characterized by the signs reflecting the systemic autoimmune process which does not correspond to any accepted diagnostic criteria for diseases such as rheumatoid arthritis, Sjogren's syndrome, systemic scleroderma, polymyositis and dermatomyositis, systemic lupus erythematosus, and mixed connective tissue diseases. Among the examined patients, the specific criteria for the above mentioned diseases were detected in the patients with UCTD from 2.7 and $20.0 \%$ more often. Bone, joint and skin phenotypic signs of dysplasia were observed in patients with GERD associated with UCTD by $4-4.5$ times more often. Summarizing the obtained data, it is necessary to consider the fact that there are many people with insignificant, barely noticeable phenotypic manifestations of dysplasia, but with many visceral signs of connective tissue weakness. This is confirmed by the fact that various abnormalities of internal organs development were detected in the majority of patients of Group II, namely in $88.0 \%$, and only in $6.6 \%$ of the patients of Group I. The obtained data on the visceral markers of undifferentiated connective tissue dysplasia were consistent with the results of studies by other authors $[15,16]$.

According to the data on daily $\mathrm{pH}$ monitoring, esophagus AET constituted $4.6 \%$ of the total monitoring period in Group I and 5.48\% in the patients of Group II being 1.19 times higher which is above normal according to the Lyon Consensus 2017 (LC-2017). In accordance with this Consensus, this parameter is considered to be significantly normal at a value of less than $4 \%$, and significantly pathological at a value above $6 \%$. If this parameter is within this interval, i.e. it falls within the limit of "unconvincing values", the number of refluxes per day are then additionally assessed [14]. The number of refluxes with $\mathrm{pH}<4$ recorded in the patients of Group I constituted $57 \pm 8$ episodes, and $79 \pm 6$ episodes in the patients of Group II. According to the Lyon Consensus, more than 80 refluxes are considered significantly increased, and less than 40 refluxes are considered a physiological norm.

\section{CONCLUSIONS}

The obtained data indicated that the number of pathological GER was significantly higher in the setting of comorbidity. Our research also showed that the chances of diagnosing Reynaud's Syndrome, arthralgia, unmotivated body weight loss, dysphagia, skin rash, oral ulcers, proximal muscle weakness in the patients with GERD associated with UCTD are higher in comparison with the patients with GERD without comorbidity $(\mathrm{p}<0.05)$. This should necessarily be taken into account in the early diagnosis and when assigning a complex therapy in case of this pathology.

\section{REFERENCES}

1. Antunes M., Scirè C.A., Talarico R. et al. Undifferentiated connective tissue disease: state of the art on clinical practice guidelines. RMD Open. 2019;4:e000786.

2. Corte T.J., Copley S.J., Desai S.R. et al. Significance of connective tissue disease features in idiopathic interstitial pneumonia. Eur Respir J. 2012;39(3):661-8.

3. Cottin V. Significance of connective tissue diseases features in pulmonary fibrosis. Eur Respir Rev. 2013 Sep 1;22(129):273-80. doi: 10.1183/09059180.00003013. 
4. Doria A., Mosca M., Gambari P.F. et al. Defining unclassifiable connective tissue diseases: incomplete, undifferentiated, or both? J Rheumatol. 2005;32:213-15.

5. Ferri C., Manfredi A., Sebastiani M. et al. Interstitial pneumonia with autoimmune features and undifferentiated connective tissue disease: Our interdisciplinary rheumatology-pneumology experience, and review of the literature. Autoimmunity Reviews.2016;15 (1):61-70.

6. Mosca M., Tani C., Vagnani S. et al. The diagnosis and classification of undifferentiated connective tissue diseases. J Autoimmun. 2014; FebMar;48-49:50-2.

7. Bodolay E., Csiki Z., Szekanecz Z. et al. Five-year follow-up of 665 Hungarian patients with undifferentiated connective tissue disease (UCTD). Clinical and experimental rheumatology. 2003;21:313-320.

8. Kinder B.W., Shariat C., Collard R.H., Koth L.L. Undifferentiated Connective Tissue Disease - Associated Interstitial Lung Disease: Changes in Lung Function. Lung. 2010 Apr; 188(2): 143-149.

9. Medsger T.A., Jr. Bombardieri S., Czirjak L. et. al. Assessment of disease severity and prognosis. Clin Exp Rheumatol. 2003;21 (29):42-46.

10. KondohY., Johkoh T., Fukuoka J. et.al. Broader criteria of undifferentiated connective tissue disease in idiopathic interstitial pneumonias. Respir Med. 2015 Mar; 109(3):389-96.

11. Romash I.B.Peculiarities of the course and treatment of gastroesophageal reflux disease in patients with syndrome of undifferentiated connective tissue dysplasia (systematic literature review). Mental Health: Global Challenges Journal. SPECIAL ISSUE "Ukraine and global processes in the area of Mental Health". 2019, December; 76-86. https://doi. org/10.32437/MHGCJ-2019(0).70.

12. Kadurina T.I., Gorbunova V.N. Connective Tissue Dysplasia: A Guide for Physicians. SPb .: Elbi-SPb. 2009. 704 s.

13. Beighton P., Paepe A., Steinmann B. International nosology of heritable disorders of connective tissue. Am. J. Med. Genet. 1998; 77(2):31-7.

14. Gyawali C., Kahrilas P., Savarino E. et al. Modern diagnosis of GERD: the Lyon Consensus Gut. 2018 Jul; 67(7): 1351-1362.

15. Dakuko A.N., Krivtsova L.A., Goncharova T.A. The role of connective tissue dysplasia in the formation of cerebral reflux in children. Bulletin of the Ivanovo Medical Academy. 2014; 19 (3): 49-52.

16. Akyüz F., Mutluay Soyer Ö. Which diseases are risk factors for developing gastroesophageal reflux disease? Turk J Gastroenterol 2017;28(1):44-47.
The work is a fragment of the research work "Diseases of internal organs in modern conditions in case of combined pathology and lesions of target organs: features of the course, diagnosis and treatment» (State registration number 0115U000995), Department of Internal Medicine, Faculty of Dental Medicine, Ivano-Frankivsk National Medical University.

\section{ORCID and contributionship:}

Iryna B. Romash: 0000-0002-9749-7783 ${ }^{A, B, C, D, E, F}$

Vasyl G. Mishchuk: 0000-0003-0428-3856 ${ }^{\text {E, }}$

\section{Conflict of interest:}

The Authors declare no conflict of interest.

\section{CORRESPONDING AUTHOR}

Iryna B. Romash

Ivano-Frankivsk National Medical University

5/7 Pylyp Orlyk st., 76010 Ivano-Frankivsk, Ukraine

tel: 0976433861

e-mail: iromash@ifnmu.edu.ua

Received: 30.07 .2019

Accepted: 20.04 .2020

A - Work concept and design, B - Data collection and analysis, C - Responsibility for statistical analysis, $\mathbf{D}$-Writing the article, $\mathbf{E}$-Critical review, $\mathbf{F}$ - Final approval of the article 